\title{
A SURVEY OF THE TWENTY-FOUR-HOUR URIC ACID AND UREA CLEARANCES IN ECLAMPSIA AND SEVERE PREECLAMPSIA ${ }^{1}$
}

\author{
By ROY W. BONSNES AND H. J. STANDER \\ (From the Department of Obstetrics and Gynecology, Cornell University Medical College, and \\ the New York Hospital, New York City)
}

(Received for publication November 3, 1945)

The uric acid clearance in eclampsia (1) and in severe preeclampsia (2), has recently been shown to be decreased. Similarly, earlier work had shown the urea clearance in this disease to be decreased (3 to 6). More recently, kidney function tests (clearance) performed with such foreign substances as inulin, diodrast and phenol red (PSP) have uniformly shown a decreased glomerular filtration rate as the outstanding alteration in kidney function found in the late toxemias of pregnancy by these techniques ( 7 to 9 ). One might expect, therefore, a general increase in the level of several blood constituents in the late toxemias of pregnancy as a consequence of this decreased glomerular filtration rate. Yet there are patients who seem to have normal N.P.N. and urea values with definite elevations in the uric acid levels.

We decided, therefore, to study further the uric acid and urea clearance in the late toxemias of pregnancy in order to determine if there were some cases which are classified clinically as either eclampsia or severe pre-eclampsia which might have a normal kidney function with respect to one metabolite, such as urea, and an abnormal or decreased function with respect to another metabolite, such as uric acid. We wished, further, to obtain as continuous a picture of the kidney function as is possible so that the changing blood levels of both the uric acid and the urea might be correlated with the clearances obtained.

The short clearance periods usually employed will yield exact information as to the kidney function during the time (at best 1 to 2 hours) the test is performed. Such data might justifiably be considered as a close approximation of the kidney function for some hours preceding and following the test if it is assumed that the rate of change in this parameter is rather slow. Now it is obvious clinically that in the toxemias of pregnancy kid-

1 This study was aided by a grant from the John and Mary Markle Foundation. ney function may change markedly from day to day and in some instances from hour to hour. Under such circumstances the usual clearance technique will yield information which is representative of the kidney function only at one particular moment.

Furthermore, if one is interested in obtaining a continuous picture of kidney function during the acute phase of the disease and during the recovery period, one might conceivably perform short period clearances daily during both the active phase of the disease and the puerperium. However, in considering a survey study such a procedure seemed both impracticable and, from the point of view of the welfare of the patient, definitely contraindicated.

It was decided, therefore, to collect 24-hour urines and to calculate the clearances on this basis. The accuracy of such clearances as compared with the short period clearances is probably reduced and these clearances may yield only figures which are of the correct order of magnitude and not the exact values. In spite of the potential sources of error which will be discussed below, the 24-hour clearances do yield information which may be obtained practically, as to the average 24-hour performance of the kidney and as to the relative rate of change in this function.

This report deals with the uric acid and urea clearances obtained by this procedure during the years 1942, 1943, and 1944, on 32 cases of late toxemia of pregnancy (eclampsia and severe preeclampsia).

\section{SUBJECTS AND METHODS}

The data reported herein were obtained upon 3 cases of antepartum eclampsia, 2 cases of questionable postpartum eclampsia and 27 cases of severe pre-eclampsia. The pertinent obstetrical data relating to these cases are given in Table $I$. Only the uric acid clearances were determined on the first 7 cases. Both the uric acid and urea clearances were obtained on the remaining 25 . The regimen upon which these patients were placed prob- 
TABLE I

Obstetrical histories of patients studied

\begin{tabular}{r|l|c|c|c|c|c}
\hline \hline $\begin{array}{c}\text { Case } \\
\text { no. }\end{array}$ & Initials & $\begin{array}{c}\text { History } \\
\text { n.Y. } \\
\text { N.Y.H. }\end{array}$ & Age & $\begin{array}{c}\text { Week } \\
\text { of preg- } \\
\text { nancy }\end{array}$ & Parity & $\begin{array}{c}\text { Complica- } \\
\text { tion }\end{array}$ \\
\hline 1 & M.P. & 312860 & 27 & 34 & $1-1-1$ & SPE \\
2 & E.D. & 308678 & 25 & 38 & $1-1-1$ & SPE \\
3 & C.C. & 319565 & 29 & 39 & $1-1-1$ & SPE \\
4 & M.C. & 328757 & 44 & 40 & $7-7-6$ & SPE \\
5 & M.B. & 317370 & 20 & 29 & $1-1-1$ & SPE \\
6 & C.R. & 318210 & 29 & 32 & $1-1-1$ & E \\
7 & H.R. & 323208 & 21 & 32 & $1-1-1$ & E \\
8 & C.S. & 331232 & 28 & 27 & $0-1-0$ & SPE \\
9 & J.U. & 164200 & 24 & 34 & $2-2-1$ & SPE \\
10 & B.S. & 297718 & 23 & 36 & $1-2-1$ & SPE \\
11 & M.H. & 334290 & 27 & 40 & $1-1-1$ & SPE \\
12 & H.P. & 340692 & 27 & 37 & $1-1-1$ & SPE \\
13 & J.P. & 343526 & 26 & 33 & $2-2-2$ & SPE \\
14 & R.O. & 345159 & 31 & 33 & $1-1-1$ & SPE \\
15 & L.E. & 345953 & 24 & 37 & $1-1-1$ & E \\
16 & M.C. & 272867 & 37 & 36 & $2-3-3$ & SPE \\
17 & V.K. & 347785 & 33 & 39 & $2-4-2$ & SPE \\
18 & J.N. & 333272 & 28 & 30 & $0-2-0$ & SPE \\
19 & M.S. & 366390 & 35 & 34 & $2-2-1$ & SPE \\
20 & V.V. & 360393 & 33 & 35 & $2-2-2$ & SPE \\
21 & J.R. & 376076 & 28 & 31 & $1-1-0$ & SPE \\
22 & J.O. & 369460 & 27 & 29 & $0-1-0$ & SPE \\
23 & A.V. & 348308 & 35 & 36 & $9-11-6$ & SPE \\
24 & S.M. & 367203 & 33 & 37 & $2-2-2$ & SPE \\
25 & G.D. & 373202 & 36 & 38 & $3-4-3$ & SPE \\
26 & B.B. & 102727 & 41 & 38 & $4-4-4$ & SPE \\
27 & A.P. & 384802 & 18 & 29 & $0-1-0$ & SPE \\
28 & A.M. & 383855 & 25 & 35 & $1-3-1$ & SPE* \\
29 & M.L. & 380679 & 39 & 38 & $1-1-1$ & SPE \\
30 & H.M. & 375749 & 27 & 40 & $1-1-1$ & Tox.-Unc. \\
31 & M.S. & 382530 & 21 & 38 & $1-1-1$ & PPE \\
32 & M.M. & 279291 & 27 & 32 & $0-4-0$ & SPE \\
\hline & & & & & & \\
\hline & E. & & & 37 & \\
\hline
\end{tabular}

$\mathrm{E}=$ Eclampsia $; \mathrm{SPE}=$ Severe preeclampsia $; \mathrm{PPE}=$ Postpartum eclampsia; Tox.-Unc. = Toxemia, unclassified. * Also had PPE.

ably does not modify the clearances except as discussed below.

The 24-hour urines were collected in the usual manner. However, it is not always possible to obtain complete 24hour specimens under these conditions. Therefore, the creatinine content of all the urines was determined and the urine volumes were corrected subsequently to an approximately constant creatinine excretion which seemed to be characteristic for the particular individual.

Blood specimens were obtained by venipuncture, generally of the cubital vein.

Uric acid was determined in Wu filtrates of plasma and in suitably diluted specimens of urine by the 1933 Folin method (10) in the first part of the work, and later by the 1922 Folin method (11) modified as previously described (12). If it was necessary to deproteinize the urine, the deproteinization was performed as described by Schaffer, et al. (2).

Urea was determined by the hypobromite manometric method of Van Slyke and Kugel (13).

Creatinine was first determined by the Folin method (14) and subsequently by the method described elsewhere (15).
The clearances were calculated in the usual way from the following data. The urine concentration of the substance in question was obtained by an analysis of a suitable aliquot of the 24-hour urine. The average plasma concentration was approximated by averaging the value obtained in blood drawn at the beginning and at the end of the 24-hour period. In the less acutely ill patients these blood specimens were taken before breakfast; those acutely ill might have been receiving an infusion of 20 per cent glucose in distilled water shortly before the blood was drawn. The urine flow was calculated by dividing the corrected urine volume in $\mathrm{ml}$. by $1440 \mathrm{~min}$ utes. At times, particularly during the post partum period when it was not necessary to obtain a blood specimen daily, the value for the days on which the blood was not taken was determined by interpolation and subsequent averaging as described above. All clearances are corrected to 1.73 sq. $\mathrm{m}$. surface area.

\section{RESULTS}

The 24-hour uric acid clearances obtained in this way during the active phase of the disease averaged $6.4 \mathrm{ml}$. per minute, and during the postpartum or early puerperium period, $10.4 \mathrm{ml}$. per minute. $^{2}$ The difference between these two average values and the differences between these and the average normal 24-hour uric acid clearance are statistically significant.

Similarly, the 24-hour urea clearance during the active phase of the disease averaged $42 \mathrm{ml}$. per minute, and during the recovery phase, $55 \mathrm{ml}$. per minute. $^{2}$ Again the difference between these two average values and the differences between these and the average normal 24-hour urea clearance are statistically significant.

The average postpartum clearances in the toxemia group should not be expected to reach normal values when all the postpartum data are averaged, since the clearances do not reach normal values until the third to fourth postpartum day.

The normal 24-hour uric acid clearance is considered to be about $12 \mathrm{ml}$. per minute. This figure has been arrived at by averaging 39 separate $24-$ hour periods obtained at various times upon 7 different patients who were being fed the usual hospital diet. There seems to be no appreciable difference between pregnant and non-pregnant women.

2 Clearances within normal limits during the active phase of the disease or definitely subnormal after the 4th postpartum day as described below are not included in these averages. 
TABLE II

Average 24-hour and short period uric acid and urea clearances

\begin{tabular}{|c|c|c|c|}
\hline \multirow{2}{*}{ Clearance } & \multicolumn{2}{|c|}{ Toxemias } & \multirow{2}{*}{ Normal } \\
\hline & Antepartum & Postpartum & \\
\hline $\begin{array}{c}24 \text { hr. UAC } \\
\frac{\mathrm{m}_{1}-\mathrm{m}_{2}^{*}}{\sigma_{D}}\end{array}$ & $6.4 \pm 2.0$ & $\begin{array}{l}10.4 \pm 2.1 \\
8\end{array}$ & $12.4 \pm 2.4$ \\
\hline $\begin{array}{c}24 \mathrm{hr} . \mathrm{UC} \\
\frac{\mathrm{m}_{1}-\mathrm{m}_{2}}{\sigma_{D}}\end{array}$ & $41.8 \pm 13.7$ & $\begin{array}{l}54.7 \pm 13.0 \\
1\end{array}$ & $63.4 \pm 8.7$ \\
\hline $\begin{array}{l}\text { Short UAC } \\
\frac{\mathrm{m}_{1}-\mathrm{m}_{2}}{\sigma_{D}}\end{array}$ & & $14.5 \pm 2.7$ & $14.0 \pm 2.9$ \\
\hline $\begin{array}{l}\text { Short UC } \\
\frac{\mathrm{m}_{1}-\mathrm{m}_{2}}{\sigma_{D}}\end{array}$ & & $75 \pm 13$ & $76 \pm 13$ \\
\hline
\end{tabular}

between the two values to the right and left immediately above. A numerical value greater than three is considered highly significant.

V.S. = very small, i.e., not significant.

The normal 24-hour urea clearance (29 periods on 6 different patients) averages $63 \mathrm{ml}$. per minute, with all clearances calculated as maximal clearances. (Complete numerical data are presented in Table II).

To determine the relationship between the clearance and the blood value of uric acid and urea, the coefficients of correlation between these values have been calculated. None of the data has been excluded. As might be expected, a significant negative correlation is found between the uric acid clearance and the plasma uric acid. (Numerical data are presented in Table III.) Similarly, a significant negative correlation is found between the urea clearance and the blood urea nitrogen. Presumably, if the few cases cited below which are exceptions to the general rule were omitted from the calculations, even better correlations would be obtained. Further, there is a significant positive correlation between the urea clearance and the uric acid clearance. It seems, therefore, that these overall data may be taken to indicate a decreased ability on the part of the kidney to excrete urea and uric acid. They also indicate a definite relationship between this kidney function and the blood levels of both uric acid and urea.

However, when the cases are considered individually certain exceptions to this general behavior are found. The majority of the patients on which there are sufficient data (17 out of 25), have both low uric acid and urea clearances during the active phase of the disease. Both these clearances have become essentially normal by the third to fourth postpartum day. In some cases there is a slight decrease in the uric acid clearance following this initial rise, with a subsequent gradual rise in the clearance to essentially normal values. Cases No. 12, 13, and 27 in Table IV are presented as examples.

There were 4 cases (No. 9, 20, 21 and 22) in which the uric acid clearance remained low during the course of the disease and returned to normal during the early puerperium, as those above. But the urea clearance seemed to remain within normal limits at all times. Case No. 9 is presented

TABLE III

Numerical data from statistical evaluations of 24-hour clearances

\begin{tabular}{|c|c|c|c|c|c|c|c|c|c|}
\hline$x$ & $\mathbf{y}$ & $\mathbf{M x}$ & $\mathbf{M y}$ & $\mathbf{N}$ & $\sigma x$ & $\sigma y$ & $\mathbf{r}$ & $\mathbf{t}$ & Equation \\
\hline $\begin{array}{l}\text { UAC } \\
\text { UC } \\
\text { UC } \\
\text { V } \\
\text { V } \\
\text { V }\end{array}$ & $\begin{array}{l}\text { PUA } \\
\text { BUN } \\
\text { UAC } \\
\text { UAC } \\
\text { UC } \\
\text { UC }\end{array}$ & $\begin{array}{l}8.16 \\
51.9 \\
51.9 \\
1.23 \\
1.27 \\
1.11\end{array}$ & $\begin{array}{c}6.61 \\
11.46 \\
7.9 \\
8.16 \\
51.9 \\
50.4\end{array}$ & $\begin{array}{l}408 \\
250 \\
250 \\
408 \\
250 \\
222\end{array}$ & $\begin{array}{r}3.29 \\
17.28 \\
17.28 \\
0.65 \\
0.65 \\
0.42\end{array}$ & $\begin{array}{r}1.57 \\
3.41 \\
3.21 \\
3.53 \\
17.28 \\
27.27\end{array}$ & $\begin{array}{l}-0.62 \\
-0.56 \\
+0.47 \\
+0.16 \\
+0.28 \\
+0.16\end{array}$ & $\begin{array}{r}16.02 \\
10.63 \\
8.41 \\
2.44 \\
4.60 \\
2.40\end{array}$ & $\begin{array}{l}y=9.03-0.03 x \\
y=17.17-0.11 x \\
y=3.42+0.87 x \\
y=7.09+0.87 x \\
y=42.40+7.44 x \\
y=38.91+10.38 x\end{array}$ \\
\hline
\end{tabular}

$\mathrm{UAC}=$ Uric acid clearance

BUN $=$ Blood urea nitrogen

$\mathbf{M x}=$ Mean of $\mathbf{x}$

$\sigma y=$ Standard deviation of $y$

PUA = Plasma uric acid

$\mathrm{V}=$ Urine flow

My $=$ Mean of $\mathbf{y}$

$\mathrm{r}=$ coefficient of correlation

calculated as follows $t=\frac{r}{\sqrt{1-r^{2}}} \cdot \sqrt{N-2}$.
$\mathrm{UC}=$ Urea clearance

$\mathrm{N}=$ Number of clearances

$\sigma \mathbf{x}=$ Standard deviation of $\mathbf{x}$

$t=$ " $t$ " value. An index of significance, 


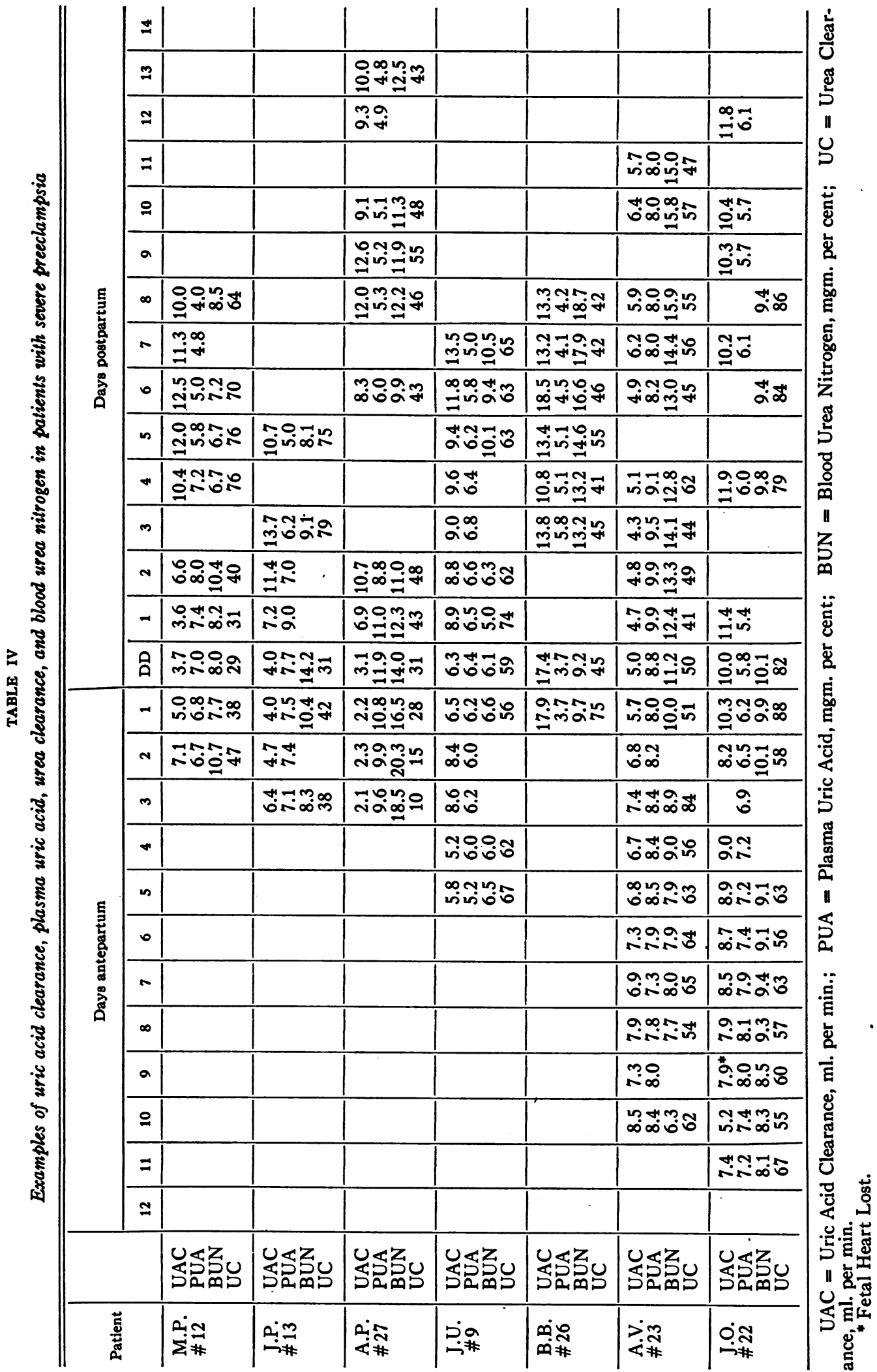


as an example in Table IV. It will be noted that in this case (and in the others) the blood urea nitrogen remained well within normal limits for a pregnant woman at term.

There were two cases (No. 26 and 31) in which the uric acid clearance remained within normal limits at all times, but the urea clearance decreased during the puerperium. In both these cases the blood urea nitrogen was increasing while the plasma uric acid remained essentially constant or decreased somewhat. Case No. 26 is presented as an example in Table IV.

And finally there were 2 cases (No. 23 and 28) in which the uric acid clearance was low during the active phase of the disease and remained low during the puerperium. In one of these the urea clearance was nearly normal but in the other it was definitely low. This last patient exhibited clinical signs and symptoms of "late postpartum eclampsia" and will be described in detail in another publication. Case No. 23 is presented as an example in Table IV.

If the fetal heart is lost these changes take place exactly as if the uterus has been emptied. The subsequent delivery of the dead fetus does not alter the clearances which remain normal. Case No. 22 is presented as an example in Table IV. In this and another instance (Case No. 21) the urea clearance remained within normal limits, but in two other cases which were not followed daily until the dead fetus had been delivered (Cases No. 8 and 22) both the uric acid and urea clearances were low and improved following the loss of the fetal heart as in the majority of the other cases cited above.

Ordinary short period uric acid and urea clearances were obtained on the majority of these cases during the early puerperium ( 5 to 15 days postpartum). These data are presented in Table V. In every instance they confirm the data obtained by the 24-hour clearances. It will be seen that the uric acid and urea clearances are within normal limits in most of the cases. The average of the uric acid clearances (excluding the two low values in parentheses) is $14.5 \mathrm{ml}$. per minute. This value is practically identical with the value previously reported by us for clinically normal women during the early puerperium (12).

The urea clearances (again excluding those values in parentheses) average $75 \mathrm{ml}$. per minute.
TABLE V

Short period uric acid and urea clearances-postpartum

\begin{tabular}{c|c|c|c}
\hline \hline $\begin{array}{c}\text { Case } \\
\text { no. }\end{array}$ & $\begin{array}{c}\text { Days } \\
\text { postpartum }\end{array}$ & UAC & UC \\
\cline { 1 - 3 } 7 & & ml. per min. & ml. per min. \\
7 & 8 & 10.1 & 56 \\
8 & $8^{*}$ & 13.3 & 74 \\
9 & 7 & 16.2 & 75 \\
12 & 12 & 16.0 & 85 \\
13 & 7 & 16.1 & 82 \\
14 & 8 & & $(113)$ \\
15 & 7 & 11.7 & 88 \\
16 & 9 & 16.8 & 85 \\
17 & 5 & & 84 \\
18 & 6 & & 74 \\
19 & 5 & & 66 \\
20 & 6 & 13.4 & $(113)$ \\
21 & 6 & 14.5 & 78 \\
22 & 8 & 10.4 & 86 \\
23 & 7 & $(6.6)$ & 66 \\
24 & 12 & 13.6 & $(113)$ \\
25 & 9 & 19.2 & 99 \\
26 & 9 & 13.5 & $(44)$ \\
27 & 15 & 10.0 & 63 \\
28 & $6 * *$ & $(7.6)$ & 57 \\
29 & 6 & 14.3 & 53 \\
31 & 15 & 18.7 & 82 \\
& & & \\
\hline
\end{tabular}

* Days following the loss of the fetal heart ** One day before convulsions.

Again this is about the same value as that obtained on clinically normal women (12).

It will be noted that the aberrant low uric acid clearances were obtained upon the patients who also had low 24-hour clearances and the low urea clearances similarly upon that one patient who exhibited low 24-hour clearances.

The three high urea clearances $(113 \mathrm{ml}$. per min.) cannot be explained.

The only really low urea clearance was obtained on one of the two cases which exhibited a decreasing clearance during the early puerperium with a normal uric acid clearance. Since the other similar case had normal clearances for both uric acid and urea fifteen days postpartum, one could suppose that the same would occur in this case, too, if another clearance had been obtained.

It appears, therefore, that in general the uric acid and urea clearances are low during the active phase of the disease, and that both these clearances return to normal in the early puerperium. Since there is a good correlation between these clearances and the blood levels of uric acid and urea, it is probable that a large portion of the increases in blood level of both uric acid and urea in severe preeclampsia and in eclampsia is due to a decreased kidney excretory function. Certain rases 
do appear, however, which are classified clinically as severe preeclampsia, which are distinct exceptions to this general behavior.

\section{DISCUSSION}

Before any attempt is made to interpret and evaluate the above data, a defense of some of the more obvious criticisms of this type of procedure should be made. Since a day by day picture of the kidney function with respect to uric acid and urea during both the active and the recovery phase of the disease was wanted, the procedure which seemed to be the best compromise was chosenthe use of 24-hour periods. But it has already been pointed out that it is nearly impossible to obtain complete collections of 24-hour urines during the active phase of the disease. And it is just as impractical to conduct the regular short period clearances each day upon such patients. We were forced to assume, therefore, that the creatinine content of the urine could be used as a guide to the accuracy of the collection of the 24-hour urine.

There is evidence in the literature which justifies our making this assumption. Smith (16) has shown that the creatinine excretion is essentially normal in severe preeclampsia. Our own experiments tend to confirm these observations for we have had some few cases in which the collections were adequate as judged by the constancy and the total amount of creatinine excreted. Even if the amount of creatinine excreted daily in sewere preeclampsia is constant and normal, it does not justify our correcting incomplete specimens to the correct 24-hour volume unless it is known that the rate of excretion of creatinine is constant over the whole 24-hour period. Though it is so in the normal, it may not be so in these cases, but the variations are probably not sufficiently large to introduce large errors. A more serious error is probably introduced into the uric acid clearance by this correction since it is known that there is a diurnal variation in the excretion of uric acid.

On the other hand, severe preeclampsia is not an all-or-none phenomenon, since clinically there are actually degrees of severity of severe preeclampsia. So it is possible that the creatinine excretion is not constant in all cases. Some of our recent data show this to be definitely true. For example, the creatinine excretion during short clearance periods on a patient with "fulminating" severe preeclampsia was approximately 80 to 90 per cent of normal, with a urea clearance of 40 per cent of normal.

In general, however, any error due to correcting the urine volume to constant creatinine excretion tends to reduce the differnce between the clearance value obtained during the active phase of the disease and that observed during the recovery phase, or that observed in normal women.

Secondly, many of these patients have received, at various times, infusions of 20 per cent glucose in distilled water. We have observed recently, in qualitative agreement with Talbot (17) and contrary to our previous observations made following a single injection of $50 \mathrm{ml}$. of 50 per cent glucose, that the continuous infusion of hypertonic glucose may increase the excretion of uric acid. These observations are published in detail in the following paper (18).

However, any increase in the uric acid clearance due to the presence of glucose will again tend to minimize the difference between the antepartum and the postpartum or normal uric acid clearances.

Thirdly, the fluid intake of these patients is limited. The urine flows can therefore be expected to be low. Our overall data indicate, however, that the low clearances are not due to the low flows only, since low clearances have been observed in many cases in spite of relatively high urine flows. Moreover, the coefficient of correlation between the urine flow and the uric acid clearance (all the data) and the urine flow and the urea clearance (both all the data and for flows of 2.00 $\mathrm{ml}$. and less) are low and of the same order of magnitude. It would appear, therefore, that the effect of the urine flow upon the clearances would be of about the same order of magnitude in both instances (for numerical data see Table III).

And lastly, it is not known how far the diet in these cases affects the uric acid clearance. We do know that the cases of mild preeclampsia which are receiving the same diet as those cases of severe preeclampsia do not exhibit these marked changes in uric acid clearance.

In spite of these potential sources of error the data have been of definite value. They show that wide variations in the clearances of these substances may occur. And in spite of the potential sources of error the agreement which has been obtained between the 24-hour clearances and the 
short period clearances when these have both been performed on the same day, have in general been much better than has been expected, during both the active phase of the disease and the puerperium.

The data presented, even if not composed of exact values, are suggestive of the actual changes which occur in the kidney function. One is forced, therefore to the tentative conclusion that the hyperurecemia of eclampsia is due in part to a decreased excretion of uric acid by the kidney. To conclude that these changes in clearance prove the hyperuricemia of eclampsia to be only due to kidney dysfunction requires the assumption be made that the rate at which uric acid is produced (or destroyed or utilized) remains constant. There are no data at hand at the present time to justify such an assumption. Therefore, the inverse relationship which is seen to exist between the uric acid clearance and the plasma uric acid level may be taken only as presumptive evidence which indicates that a decrease in kidney function is one of the factors operating toward the maintenance of a hyperuricemia. However, the significant positive correlation between the uric acid clearance and the urea clearance, and the significant negative correlation between the urea clearance and the blood urea nitrogen, tend to offer additional evidence to support the contention that a part of the elevation seen in both the blood uric acid and in the blood urea is due to a decrease in kidney function.

In terms of the present day concept of kidney function, this decrease in uric acid and urea clearance which is observed in the majority of cases can probably be ascribed to a decrease in the glomerular filtration rate. The maintenance of a normal rate of creatinine excretion can be attributed to an increased tubular secretory activity. Such an interpretation is in complete accord with the observations made previously by other methods in this and in other laboratories (7 to 9).

Whether there is or is not a decrease in the glomerular filtration rate in those cases in which there is a decreased uric acid clearance and a normal urea clearance, or vice versa, cannot be determined from these data. Regardless of this particular point, one must postulate that wide fluctuations in the tubular reabsorption rate occur in these instances if one is to ascribe the observed phenomena to alterations in kidney function. The answer to this question can be had by determining the glomerular filtration in patients who exhibit these contrasts. We are now collecting such data. A few preliminary experiments already performed indicate that deviations from normal tubular activity do occur in certain cases of severe preeclampsia.

\section{SUMMARY AND CONCLUSIONS}

The 24-hour uric acid clearance has been determined daily in 32 obstetrical patients with either eclampsia or severe preeclampsia as a complication during the course of the disease and during recovery from the disease. The 24-hour urea clearance has also been determined in 23 of these cases. The uric acid and urea clearances were found to be subnormal during the active phase of the disease and to return to nearly normal values by the third to fourth postpartum day in the majority of cases ( 15 out of 23 ). However, certain exceptions to this general behavior were found. Four patients showed subnormal uric acid clearances during the disease, which improved during the early puerperium as above. But the urea clearances remained normal throughout the period that these patients were under observation. Two patients showed apparently normal uric acid clearances and urea clearances during the antepartum, but decreasing urea with normal uric acid clearances during the early puerperium. And finally, two others had subnormal uric acid clearances during both the antepartum and the early puerperium. In one of these cases the urea clearance was a low normal while in another it was definitely subnormal. Short period uric acid and urea clearances had become normal in the majority of cases in the early puerperium. Those cases in which the short period clearances were not normal were the same as those few which exhibited abnormal 24-hour uric acid clearances. The sources of error and the possible interpretations of these data are discussed.

It is concluded that there may be a hyperuricemia or a hyperuremia, or both, in eclampsia and severe preeclampsia, and that these elevations may be due largely to an altered kidney function. A decrease in the glomerular filtration rate may serve to explain the phenomena in the majority of cases. However, some of the exceptional cases can be explained only by postulating a change in 
the rate of tubular reabsorption of uric acid and urea. The possibility also exists that some of these changes may be due to alterations in the metabolism of these substances.

We wish to express our thanks to the many members of the house and nursing staffs whose cooperation has made this study possible. Many of the analyses were performed by Miss Hertha H. Taussky, M.S., some of the urea analyses by Mr. Nelson Osterberg, and the drudgery of the statistical analyses by Mrs. Eleanor M. Brew.

\section{BIBLIOGRAPHY}

1. Nayar, A. S. M., Eclampsia. A clinical and biochemical study. II. Biochemical investigation of eclampsia. J. Obst. and Gynaec. Brit. Emp., 1940, 47, 404.

2. Schaffer, N. K., Dill, L. V., and Cadden, J. F., Uric acid clearance in normal pregnancy and preeclampsia. J. Clin. Invest., 1943, 22, 201.

3. Stander, H. J., Ashton, P., and Cadden, J. F., The value of the various kidney function tests in the differentiation of the toxemias of pregnancy. Am. J. Obst. and Gynec., 1932, 23, 461.

4. Cadden, J. F., and McLane, C. M., Study of various kidney function tests in relation to toxemias of pregnancy. Surg., Gynec. and Obst., 1934, 59, 177.

5. Dieckmann, W. J., Renal function in toxemias of pregnancy. Am. J. Obst. and Gynec., 1935, 29, 472.

6. Brown, D. B., The value of the urea clearance test in pregnancy. J. Obst. and Gynaec. Brit. Emp., 1938, 45, 786.

7. Corcoran, A. C., and Page, I. H., Renal function in late toxemia of pregnancy. Am. J. M. Sc., 1941, 201, 385.
8. Wellen, I., Welsh, C. A., Taylor, H. C., Jr., and Rosenthal, A., The filtration rate, effective renal blood flow, tubular excretory mass and phenol red clearance in specific toxemia of pregnancy. $\mathrm{J}$. Clin. Invest., 1942, 21, 63.

9. Dill, L. V., Isenhour, C. E., Cadden, J. F., and Schaffer, N. K., Glomerular filtration and renal blood flow in the toxemias of pregnancy. Am. J. Obst. and Gynec., 1942, 43, 32.

10. Folin, O., Standardized methods for the determination of uric acid in unlaked blood and in urine. J. Biol. Chem., 1933, 101, 111.

11. Folin, O., A system of blood analysis. Supplement IV. A revision of the method for determining uric acid. J. Biol. Chem., 1922, 54, 153.

12. Bonsnes, R. W., Dill, L. V., and Dana, E. S., The effect of diodrast on the normal uric acid clearance. J. Clin. Invest., 1944, 23, 776.

13. Van Slyke, D. D., and Kugel, V. H., Improvements in manometric micro-Kjeldahl and blood urea methods. J. Biol. Chem., 1933, 102, 489.

14. Folin, $O$., On the determination of creatinine and creatine in urine. J. Biol. Chem., 1914, 17, 469.

15. Bonsnes, R. W., and Taussky, H. H., On the colorimetric determination of creatinine by the Jaffe reaction. J. Biol. Chem., 1945, 158, 581.

16. Smith, O. W., Creatinine excretion in women: data collected in the course of urinalysis for female sex hormones. J. Clin. Endocrinol., 1942, 2, 1.

17. Talbot, J. H., Oxford Medicine, Oxford University Press, New York, 1943. Vol. IV, part 1, chapter IV (Gout).

18. Bonsnes, R. W., and Dana, E. S., On the increased uric acid clearance following the intravenous infusion of hypertonic glucose solutions. J. Clin. Invest., 1946, 25, 386. 